DAYDREAMING AND SOCIAL COGNITION

Daydreaming to navigate the social world: What we know, what we don't know, and why it matters

\author{
Giulia Lara Poerio and Jonathan Smallwood \\ University of York
}

Author note

Giulia Lara Poerio, Department of Psychology, University of York; Jonathan Smallwood, Department of Psychology, University of York.

Acknowledgements/funding sources. We thank David Stawarczyk and Arnaud D’Argembeau for providing us with results from their 2015 meta-analysis. This work was supported by the ERC [grant number: 646927].

Correspondence concerning this article should be addressed to Giulia Lara Poerio, Department of Psychology, University of York, Heslington, York, YO10 5DD, UK. Contact: giulia.poerio@york.ac.uk 


\begin{abstract}
A substantial portion of daily life is spent daydreaming; that is, engaged in thought independent of, and unrelated to, goals in the external environment. We argue that this naturally-occurring, unconstrained, cognition is a vital, but currently underappreciated, form of social cognition, which enables navigation of the social world. First, we present the results of a meta-analysis of neuroimaging studies which illustrate the shared neural basis of daydreaming and social cognition (regions of the anterior temporal lobes and the posterior cingulate cortex). Second, we review evidence regarding the frequency, correlates, and adaptive outcomes of social daydreaming, cumulative findings that point to the adaptive value of imaging others during this offline state. We end by encouraging cross-fertilization between daydreaming research and domains of social psychology (goal pursuit, social interactions, and close relationships), which we hope will foster mutually beneficial directions for understanding the role that unconstrained thinking plays in social life.

Keywords: Daydreaming, mind-wandering, social cognition, default mode network, goals, imagination, social interaction, close relationships, need to belong, experiencesampling methodology.
\end{abstract}


DAYDREAMING AND SOCIAL COGNITION

\section{Daydreaming to navigate the social world: What we know, what we don't know, and why it matters}

Positive and lasting social relationships are vital for health and happiness, and much of our thoughts, feelings, and behaviors are fundamentally motivated by the need for social connection (Baumeister \& Leary, 1995; Deci \& Ryan, 2000). The importance of social relationships is strikingly illustrated by the negative effects of inadequate social connection. A meta-analysis of 70 prospective studies with nearly 3.5 million participants estimated that loneliness increases one's likelihood of death by $26 \%$, posing an equivalent risk to mortality as well-known health risks (Holt-Lunstad, Smith, Baker, Harris, \& Stephenson, 2015).

Clearly, successfully navigating the social world, forming and maintaining close relationships, is essential. In this paper, we argue that daydreaming is vital to this process because it can facilitate the pursuit of social goals needed for social connection.

In contrast to traditional goal-directed cognition, daydreaming is typically spontaneous, unconstrained, and occurs 'offline' independently of the external environment. Although the scientific study of daydreaming and mind-wandering has burgeoned, particularly within cognitive neuroscience, the adaptive value of daydreaming for social life remains relatively unexplored. We introduce and describe the ubiquity and importance of daydreaming, including its core characteristics, neural basis, and consequences. We review evidence consistent with the proposal that daydreaming is a prevalent and socially adaptive form of cognition by: (a) showing that daydreaming and social cognition have a shared neural basis, and (b) reviewing research that points to the benefits of social daydreaming for social well-being and relationships. We end by describing how a more comprehensive account regarding the adaptive value of social daydreaming would benefit from integration with social psychological research, which we hope will galvanize future collaborative efforts.

\section{What is daydreaming?}




\section{DAYDREAMING AND SOCIAL COGNITION}

The 2013 blockbuster, The Secret Life of Walter Mitty, tells the story of chronic daydreamer, Walter, who launches into vivid, fanciful, daydreams to escape his lackluster life. The film illustrates long-standing negative conceptions of daydreaming, which are reflected in pejorative terms such as "off with the fairies", "zoning out", and "idle wool gathering”. Early psychology texts echo this notion of daydreaming as futile, and daydreamers as lazy and inattentive. Freud considered daydreaming as a manifestation of hysteria, neurosis, and psychopathology (e.g. Freud, 1908); an early article on daydreaming argued that it "results in a sort of mental flabbiness" that causes inferior scholarship (Brown, 1927, p. 279); and an educational psychology textbook warned that daydreaming may create "severe mental disorders" (Cronbach, 1957, p. 552).

Modern psychological research defines daydreaming differently. Daydreaming (also referred to as mind-wandering, spontaneous thought, off-task thinking) can be defined as mental content that is stimulus-independent and task-unrelated (Stawarczyk, Majerus, Maj, Van der Linden \& D'Argembeau, 2011). Daydreaming is stimulus-independent because its content is not directly related to the processing of the immediate environment (it is internallygenerated); it is task-unrelated because its content is unrelated to the progression or completion of the current goal(s) in the external environment. Although useful, this negative definition is inherently unsatisfactory because it defines daydreaming as what is not rather than what it is. Rather than viewing daydreaming as a passive state defined in relation to the external present, daydreaming should be considered an active process occurring independently of events in the environment: the thoughts experienced during the offline state are self-generated and support the capacity to focus on goals that extend beyond the present.

Estimates indicate that between $30-50 \%$ of waking life is spent daydreaming (Killingsworth \& Gilbert, 2010; Klinger \& Cox, 1988). Most convincingly, in a large-scale investigation, daydreaming was reported, on average, $47 \%$ of the time (Killingsworth \& 
DAYDREAMING AND SOCIAL COGNITION

Gilbert, 2010). Similar frequencies of daydreaming in daily life have been reported in the United Kingdom (36\%: Poerio, Totterdell, \& Miles, 2013), the U.S.A (26\%: Franklin et al., 2013; 30\%: Kane et al., 2007, McVay, Kane, \& Kwapil, 2009) and China (60\%: Song \& Wang, 2012) as well as during laboratory studies (e.g. Smallwood et al., 2004; Smallwood, Nind, \& O’Connor, 2009; Smallwood, O’Connor, Sudberry, \& Obonsawin, 2007; Smallwood et al., 2011). The prevalence of daydreaming and its broad conception means that daydreaming encompasses a range of self-generated thoughts such as rumination, worry, fantasy, mental time travel, intrusive thoughts, and involuntary autobiographical memories. Daydreaming therefore involves different kinds of self-generated thoughts which can vary on several dimensions (e.g. emotional content, time orientation). Appreciating and measuring this heterogeneity is essential to understanding when daydreaming is (mal)adaptive, a point which we later return to.

\section{Daydreaming as the default mode of thought}

Despite the ubiquity of daydreaming, psychological science has historically focused on externally directed, task-related, and experimentally-induced, thinking (Christoff, 2012). However, the last 20 years has seen a shift towards the systematic study of internallygenerated unconstrained cognition. This owes much to the discovery of the Default Mode Network (DMN; Greicius, Krasnow, Reiss, \& Menon, 2003; Raichle et al., 2001), which showed that, even when participants are not performing any external task, the brain remains active, consuming between 60-80\% of all brain energy (Raichle, 2010). The DMN is a largescale constellation of brain regions which include the medial prefrontal and cingulate cortex, the medial temporal lobe, the lateral parietal cortex, and areas of the cerebellum and the striatum (Buckner, Andrews-Hanna, \& Schacter, 2008). At rest, these regions exhibit a pattern of coherent temporal behavior (Greicius et al., 2003) and are deactivated during cognitively demanding, and externally-focused, tasks (Fox et al., 2005). 
DAYDREAMING AND SOCIAL COGNITION

Daydreaming has been implicated as the 'default mode' of thought because it is consistently associated with the DMN. This link has been established by studies showing that: (a) daydreaming during conditions of low cognitive demand is positively associated with DMN activity (Mason et al., 2007; McKiernan, D’Angelo, Kaufman, \& Binder, 2006), (b) that participants' with a greater propensity to daydream show greater DMN recruitment (Mason et al., 2007), and (c) that DMN regions show significantly more activation immediately before daydreaming (Allen et al., 2013; Christoff et al., 2009; Stawarczyk, Majerus, Maquet, \& D’Argembeau, 2011). A recent meta-analysis confirmed that studies of daydreaming and spontaneous thought reliably involve major areas of the DMN (Fox, Spreng, Ellamil, Andrews-Hanna, \& Christoff, 2015).

\section{The adaptive value of daydreaming}

Descriptive and neural evidence shows that daydreaming occupies a prominent position in mental life. One conclusion that naturally follows from this ubiquity is that daydreaming is a mental process that confers advantage and promotes species survival (Klinger, Barta, \& Mahoney, 1976; Klinger, 2013). Although daydreaming may have adaptive value, it can be costly as well as beneficial. Daydreaming is detrimental to performance in laboratory tasks (e.g. reading comprehension, sustained attention, and memory; Mooneyham \& Schooler, 2013), during daily activities (McVay et al., 2009), when driving (He, Becic, Lee, \& McCarley, 2011), and in educational contexts (Robison \& Unsworth, 2015); it can have negative effects on happiness (Killingsworth \& Gilbert, 2010; Poerio et al., 2013), and physiological health (Ottaviani, \& Couyoumdjian, 2013). However, daydreaming has also been linked to a number of potential benefits, including future planning (Baird et al., 2011), creativity (Baird et al., 2012), problem-solving (Ruby, Smallwood, Engen, \& Singer, 2013b), and the ability to delay gratification (Smallwood, Ruby, \& Singer, 2013a). More broadly, researchers have theorized that daydreaming enables individuals to 


\section{DAYDREAMING AND SOCIAL COGNITION}

keep track of, organize, and achieve multiple goals pursuits (Klinger, 1975, 1990, 2009, 2013), facilitates socio-emotional development (Immordino-Yang, Christodoulou, \& Singh, 2012), and supports memory consolidation and decision-making (Christoff, Gordon, \& Smith, 2011).

Despite evidence for the benefits of daydreaming, evidence for its adaptive value is relatively scarce compared to robust evidence for its costs. Indeed, a review identified 29 studies revealing the costs of daydreaming and only six that spoke to its potential benefits (Mooneyham \& Schooler, 2013). Research on the potential adaptive value of daydreaming is also typically weaker, and based on inferences rather than direct empirical support. For instance, the idea that daydreaming benefits future planning is inferred from evidence that daydreams are predominately future, self, and goal-focused (Baird et al., 2011), rather than linking daydreaming to demonstrable outcomes such as later plan execution. Likewise, although daydreaming has been correlated with better problem-solving and the delay of gratification, it is not clear whether daydreaming per se predicts these skills or whether these capacities share common features which explains their association (e.g. the reliance on autobiographical memory, Ruby et al., 2013a, or the ability to guard an internal goal from external interference, Smallwood et al., 2013).

We believe that a key, and timely, issue is to provide a more comprehensive account of the adaptive value of daydreaming. Such an account should focus on the adaptive value of daydreaming for navigating the complex and dynamic social relationships that are so vital for physical and psychological wellbeing. What does it mean for daydreaming to be adaptive? Broadly, a process can be considered adaptive if it facilitates the pursuit of meaningful personal goals (i.e. desired end-states). Successful goal pursuit is essential for an individual to interact with, and survive, in the environment, and to achieve basic psychological needs, such as those related to autonomy, competence, and social connection (Deci \& Ryan, 2000). 


\section{DAYDREAMING AND SOCIAL COGNITION}

Processes that facilitate the pursuit and achievement of personal goals can be conceptualized as adaptive; those that interfere with or hinder goal pursuit and achievement can be conceptualized as maladaptive. In terms of social adaptiveness, daydreaming would primarily be adaptive to the extent that it directly or indirectly helps an individual achieve the need for social connection. The need for social connection can be thought of as a higher-order desired end state that organizes lower level socio-emotional goals (Elliot \& Fryer, 2008). These goals may be instrumental (e.g. getting a new colleague to like you) or hedonic (e.g. avoiding feelings of loneliness), occur at different time frames, and levels of abstractness (e.g. asking someone on a date versus being in a happy relationship).

We emphasize the need to link the adaptiveness of daydreaming to an individual's meaningful personal goals because a failure to do so can often lead to the conclusion that daydreaming merely represents a lapse in attention. For example, researchers often view daydreaming negatively because it interferes with performance on a variety of cognitive tasks (Mooneyham \& Schooler, 2013). In one sense, daydreaming is maladaptive because it interferes with the pursuit of current task goals (e.g. responding quickly and accurately). However, in a wider sense, daydreaming during a task may be far from costly when it facilitates the pursuit of meaningful goals that extend beyond the here-and-now (e.g. by providing a useful insight into a personal problem). Indeed, daydreaming typically reflects engagement with personal goals (e.g. Baird et al., 2011; Klinger, 1996; Poerio et al., 2013) and its frequency and content can be primed by individuals' goals and associated emotional states (Antrobus, Singer, \& Greenberg, 1966; McVay \& Kane, 2013; Smallwood et al., 2011; Stawarczyk, Majerus, \& D’Argembeau, 2013). Viewing daydreaming within the context of an individual's wider personal goals is imperative: if we continue to assume that daydreaming represents absent-mindedness, or an inattentive nature, then we run the risk of 


\section{DAYDREAMING AND SOCIAL COGNITION}

underestimating, and misrepresenting, its potential adaptive value. With this in mind, we now review evidence for the premise that daydreaming is adaptive for social life.

\section{Daydreaming and social cognition}

Social cognitive processes are essential for interacting in the social environment to pursue and achieve meaningful social goals. Core components of social cognition include (among others) accurate reasoning about others thoughts, feelings, and behaviors, distinguishing the self from others, and predicting and explaining others behavior (Amodio \& Frith, 2006). Social cognition research typically examines these processes as they occur online; that is, during externally-directed social cognition tasks. However, as well as occurring online in the social environment, we suspect that much of what facilitates the achievement of important social goals is our ability to engage social cognition offline during daydreaming (e.g. imagining past and possible future interactions). One way to provide support for this idea is to demonstrate that the neural mechanisms that underlie more obvious, and well-established, forms of social cognition are also implicated in daydreaming.

To this end, we examined the overlap between brain regions involved in the daydreaming state (specific regions of the DMN) and during social cognition tasks. We performed a meta-analysis to provide spatial brain activation maps for studies using the term "social cognition" using the meta-analytic search tool Neurosynth (Yarkoni, Poldrack, Nichols, Van Essen, \& Wagner, 2011). The database was accessed on 22.02.16 and identified 166 studies, which we compared with a meta-analysis from nine studies on mind-wandering (Stawarczyk \& D’Argembeau, 2015). This revealed a pattern of spatial overlap in regions of the anterior temporal lobes and posterior cingulate cortex (shown in yellow in Figure 1).

This pattern of spatial overlap illustrates the dependence of daydreaming and social cognition on shared neural processes. Although our analysis is specific to regions involved in daydreaming (rather than the DMN as a whole), it is consistent other work indicating that 


\section{DAYDREAMING AND SOCIAL COGNITION}

social cognition and the DMN share a common neural basis. For example, across 12 studies Schilbach et al. (2008) noted that activations in the DMN were comparable to activated brain regions during a number socio-emotional tasks including: the monitoring of others' actions, distinguishing self from other, and social interaction. Likewise, Mars et al. (2012) examined brain regions activated in social cognition tasks from 216 experiments, again demonstrating the substantial overlap between DMN and social cognition (particularly theory of mind, mentalizing, and empathy) (see also Li, Mai, and Lui, 2014 for a narrative review). The fact that social cognition tasks typically involve emotional, as well as cognitive, aspects has led to the additional suggestion that there is a common network of brain regions associated with unconstrained cognition (DMN), emotional, and social, processing (Amft et al., 2015; Schilbach et al., 2012). Our analysis supports these assertions by highlighting shared neural processes between daydreaming and social cognition in two key areas of the DMN. Furthermore, our findings provide specific support for the idea that the neural mechanisms that support core aspects of deliberate, online, social cognition are also involved during the unconstrained, offline, daydreaming state.

\section{Social daydreaming and adaptive socio-emotional outcomes}

The various socio-emotional processes that would enable successful navigation of the social world (e.g. perspective taking, mentalizing) show significant overlap with the brain regions that are activated when people daydream, a finding that implicates daydreaming as a potentially adaptive form of social cognition. Descriptive evidence supports the idea that daydreaming often involves social cognition because daydreams are predominately social (i.e. involve the mental representation of other people). In a large scale survey $(\mathrm{N}=17,556)$ three-quarters of respondents reported 'frequently' or 'always' experiencing social daydreams (Mar, Mason, \& Litvack, 2012); experience-sampling also shows that naturally occurring daydreams are predominately social (71\%; Song \& Wang, 2012). Research on 


\section{DAYDREAMING AND SOCIAL COGNITION}

imagined interactions - a type of daydreaming involving an internal dialogue with close others (Honeycutt, Zagacki, \& Edwards, 1990) - indicates that this type of social daydreaming is also common and typically centered on upcoming and past communicative encounters (Honeycutt, Vickery \& Hatcher, 2015). Investigations examining the underlying factor structure of daydreaming during laboratory tasks and resting state conditions also highlight the preponderance of social daydreaming (Diaz et al., 2013; Gorgolewski et al., 2014; Ruby et al, 2013a, 2013b).

Despite evidence demonstrating the shared neural basis of social cognition and daydreaming, and the preponderance of social daydreaming, this alone is not enough to provide convincing evidence that daydreaming is socially adaptive. The correlates of social daydreaming shed more light on this issue and are consistent with the idea that aspects of social daydreaming may be related the ability to form and maintain satisfying social relationships. Daydreaming more frequently about close others is associated with greater social well-being (greater perceived social support and life satisfaction; Mar et al., 2012). Likewise, more frequent and positive imagined interactions are associated with less loneliness (Honeycutt, Edwards, \& Zagacki, 1989) and greater relationship satisfaction (Honeycutt \& Keaton, 2012). These investigations are consistent with the idea that the frequency and content of social daydreams might have a positive impact on social relationships. However, the cross-sectional and retrospective nature of these studies precludes firm conclusions about whether social daydreams have a causal impact on the achievement of social goals that would promote the formation and maintenance of social relationships. It is equally likely, for example, that these features of social daydreaming are a consequence, rather than a cause, of having positive social relationships.

Our recent research has focused on the proximal and distal outcomes of daydreams, providing more direct evidence for the idea that social daydreams have adaptive implications 


\section{DAYDREAMING AND SOCIAL COGNITION}

for hedonic and instrumental social goals. By sampling naturally occurring daydreams, we have shown that social daydreaming can represent a means of achieving feelings of social connection, serving immediate socio-emotional regulation goals (Poerio, Totterdell, Emerson, \& Miles, 2015b). Social (but not non-social) daydreams about close others had an immediate socio-emotional benefit by promoting positive social feelings of love and connection. The effect of social daydreaming on social emotions was greater when participants were lacking in these feelings before their daydreaming, a finding suggesting that daydreaming represented successful attempts to regulate negative social emotions through imaginative activity.

In a follow up study, daydreaming about close others under explicit conditions of induced social threat (a loneliness manipulation) served to regulate the socio-emotional needs of participants (Poerio, Totterdell, Emerson, \& Miles, 2015a). Participants who imagined interacting with a close significant other (vs. completing a control task or daydreaming about a pleasant but non-social event) showed increased feelings of connection, love, and belonging, a finding consistent with the idea that daydreaming promotes the achievement of contextually relevant hedonic goals. Social daydreaming also had a causal impact on later social behavior; participants who engaged in social daydreaming expressed less of a desire to interact with others in a subsequent task (see Figure 2). This result was consistent with the idea that social daydreaming had regulated the thwarted need for social connection, because participants who had engaged in social daydreaming (unlike other participants) did not need to engage in further attempts to regulate their emotions through social interaction.

In addition to the proximal effects of social daydreaming on hedonic goals, we have demonstrated that social daydreaming can promote adaptation to a new social environment over time. We sampled naturally occurring daily social daydreams from 103 participants for one month during a life transition - their transition to university (Poerio, Totterdell, Emerson, \& Miles, 2016). During this time, social daydreams became more constructive both in terms 


\section{DAYDREAMING AND SOCIAL COGNITION}

of their content (they became less fanciful and increasingly involved close others) and their emotional outcomes (they were increasingly associated with feeling more connected and less lonely), a pattern of change representing a positive reaction to changes in social circumstances during daydreaming. Crucially, this constructive response to a novel social environment then predicted adaptive outcomes relevant to that situation (less loneliness and greater social adjustment to university life). The longitudinal nature of this study allowed us to determine whether aspects of social daydreaming and their dynamics predicted later outcomes relevant to thriving in a personally meaningful and novel social environment. As such, these data provide convincing evidence that social daydreaming can be adaptive.

A core assumption underlying our findings is that social daydreaming is not inherently adaptive or maladaptive but that this depends on the content of thought. This is mirrored by perspectives which emphasize that daydreaming is not a homogenous experience and that the relationship between daydreaming and various outcomes depends on how people regulate their thoughts (Smallwood \& Andrews-Hanna, 2013). One approach to examine how the content of thought is related to various outcomes has been to generate categories of thought using a technique called Multi-Dimensional Experience-Sampling (MDES; Ruby et al., 2013a, 2013b). Participants rate the extent to which their sampled thoughts pertain to various categories (e.g. future-orientated, past-orientated, self-focused, other-focused, negative-positive) which are decomposed into factors using principal components analyses (see Figure 2). Consistently emerging patterns of covariance include components where thoughts reflect thinking about: others in the past, the self in the future, or vary in their emotional valence (positive-negative).

These factors show predictive value for a number of variables, demonstrating the value of conceptualizing daydreaming as heterogeneous. For example, past-other related thoughts predict less positive mood whereas future-self thoughts predict more positive mood 


\section{DAYDREAMING AND SOCIAL COGNITION}

(Ruby et al., 2013a). Thought factors have also been linked to physiological stress markers: for instance, future-self related thoughts are associated with lower cortisol levels whereas negative thoughts are associated with higher cortisol levels (Engert, Smallwood, \& Singer, 2014). Neuroimaging has also identified that many of these different types of thought depend on a process of integration from regions in the temporal lobe by the posterior cingulate (Smallwood et al., 2016), both regions of cortex that our meta-analysis identified as important in social cognition and daydreaming. Other research shows that characteristics of commonly occurring daydreams are associated with individual differences in affective experiences (Andrews-Hanna et al., 2013). For example, higher levels of depression and negative affect are associated with negative and personally significant thoughts whereas higher levels of trait mindfulness is associated with positive, concrete, and less personally significant thoughts. Taken together, these findings emphasize the heterogeneity of daydreaming and the need to consider the content of the experience. Rather than formulating general conclusions about the adaptive or maladaptive nature of (social) daydreaming research must consider how the content and form of daydreams are related to specific adaptive outcomes. Doing so will provide a more nuanced account that specifics the conditions under which daydreaming is (mal)adaptive and for what.

\section{Integration with social psychological research and theory}

The findings reviewed above suggest that social daydreaming may have adaptive value depending on its content, findings consistent with the proposal that naturally occurring social daydreams have an impact on personally meaningful hedonic and instrumental goals. The neural evidence reviewed suggests that the mechanisms through which these effects emerge lie in the ability to engage in constructive forms of offline social cognition during daydreaming. However, linking these two lines of research to examine when and how social daydreaming is adaptive would provide a more comprehensive account of offline social 


\section{DAYDREAMING AND SOCIAL COGNITION}

cognition and its importance for social life. We believe cross-fertilization with social psychological research and theory would benefit such an account because it would help to link the content and nature of social daydreams with its proposed adaptiveness.

\section{Daydreaming and goal pursuit}

We have emphasized the need to connect daydreaming to the pursuit and achievement of meaningful social goals. A central issue that requires additional work is whether and how the content and processes involved in social daydreaming increase the likelihood of social goal achievement. We suggest that research should focus more intently on causally linking the content and process involved in daydreaming to measurable goal-relevant outcomes (e.g. goal progress or achievement, socio-emotional well-being, successful social interactions), because, if daydreaming is adaptive, then it should produce changes in outcomes that facilitate the pursuit or attainment of meaningful social goals.

With an abundance of research and theory on goal pursuit and achievement processes, social psychological approaches could shed new light on whether and how daydreaming relates to social goal realization. The relationship between social daydreaming and goal achievement is likely to be multiply determined and it would be important for research to examine both the proximal and distal effects of social daydreaming on later goal pursuit and achievement. For example, research could examine how daydreams influence the motivation and commitment to pursue goals, which then translates into achievement (Oettingen, 2000). Research on mental simulation and goal pursuit has converged upon the idea that how goals are mentally represented predicts goal achievement, such that imagining the pursuit (rather than the successful attainment) of goals is more conducive to their achievement (for a review see Freund \& Hennecke, 2015). Future work might profit from examining the extent to which the mental representation of social goals during naturally occurring daydreams mirrors this well established finding. 
DAYDREAMING AND SOCIAL COGNITION

Given existing links with daydreaming and autobiographical planning (Baird et al., 2011), research could explore whether daydreams promote social goal achievement through spontaneous if-then planning (Gollwitzer \& Sheeran, 2006). Imagining the pursuit of social goals during daydreaming may specify actions and opportunities to act, which, in turn, result in more automatic and efficient forms of goal striving (Webb \& Sheeran, 2007). In an initial attempt to address this question, Medea et al. (2016) asked participants to describe three of their most important goals and found that when they were asked to re-describe them following performing a simple non-demanding task, the amount of spontaneous thoughts associated with the self in the future predicted increases in the concreteness of their goals. Furthermore, because daydreams are typically repetitive, the processes that link daydreaming to goal pursuit may be cumulative, iterative, and likely to change depending on current goal progress. This could be examined by linking daydreaming with goal monitoring, (Harkin et al., 2015), the use of imagination to promote persistence and effort during goal striving over time (Markman \& McMullen, 2003), and the ability to learn from past failures transforming them into future success (counterfactual thinking; Roese, 1994).

\section{Daydreaming and social interaction}

Examining the effect of social daydreaming on social interaction is likely to be an especially useful way to link daydreaming with social goal achievement in specific social contexts. Indeed, previous research on directed, rather than naturally-occurring, social imagination shows that imagining future social interactions can be beneficial. For example, participants instructed to mentally plan a conversation displayed less non-verbal displays of anxiety during subsequent social interaction (Allen \& Honeycutt, 1997). This suggests that planning in imagined social interactions is linked with reduced feelings of social anxiety, although whether reduced anxiety then translates into more effective communication is an open question. Other research indicates that imagining the potential negative (compared to 


\section{DAYDREAMING AND SOCIAL COGNITION}

positive) aspects of an upcoming social interaction can be advantageous for that interaction when individuals respond with positive reactions and potential behavioral strategies (Showers, 1992). In the intergroup domain, a substantial body of research on imagined intergroup contact has shown that imagining interacting with an outgroup member is associated with benefits such as positive attitudes towards outgroup members and increased outgroup trust (Miles \& Crisp, 2014), features that would presumably foster more cooperative and tolerant interactions where they to occur. More recent research has causally linked imagined contact to the quality of later social interaction (West, Turner, \& Levita, 2015) and more prosocial behavior towards outgroup members (Meleady \& Seger, 2016). These findings indicate that directed imagination of initial social encounters can benefit social interaction success, a key process in forming and maintaining social relationships. Whether similar results would be obtained during naturally occurring social daydreams which are based on personal goals, and within pre-existing (rather than novel) relational contexts, is likely to be a fruitful line of enquiry.

\section{Daydreaming and relationship behaviors}

In addition to the processes involved in successful goal realization more generally (e.g. planning and intention formation), and those involved in social interactions (e.g. rehearsal and anxiety reduction), research would benefit from examining how social daydreaming supports the ability to maintain positive relationships. One approach would be to examine the extent to which aspects of daydreaming are related to relationship enhancing behaviors (e.g. providing social support, fostering intimacy, or resolving relational conflict) (Reis \& Gable, 2003). Here the focus would be on understanding how aspects of social cognition (e.g. perspective taking, metalizing) during daydreaming predict later relational behaviors. For example, mentally simulating different combinations and possible alternative outcomes of relational situations (e.g. by drawing on past experience and knowledge about 


\section{DAYDREAMING AND SOCIAL COGNITION}

others) may result in more effective social problem-solving and conflict resolution (cf.

Moulton \& Kosslyn, 2009). Likewise, reflecting on how other people think, feel, and behave during daydreaming may result in greater empathetic understanding and social sensitivity (Decety \& Jackson, 2006). Such enhanced interpersonal skills may then translate into more sensitive and responsive interpersonal behavior, a key factor in developing and maintaining intimacy within social relationships (Reis \& Gable, 2015).

\section{Conclusion}

Future research efforts will profit from linking daydreaming research with these (and other) well-established areas in social psychology. Drawing on these existing literatures will help to formulate key constructs and processes that describe when and why aspects of social daydreaming will be (mal)adaptive. Ideally, future research would examine social daydreaming within the context of meaningful social relationships and might therefore capitalize on situations where relational goals are important, such as newly forming romantic or organizational relationships, or situations undergoing changes in social relationships, such as bereavement, divorce, and geographical relocation. Daydreaming research is inherently challenging because, unlike studies of mental simulation or social cognition tasks, daydreaming must be observed and captured rather than manipulated by experimental instruction (Smallwood, 2013). We would therefore advocate the use of intensive longitudinal methods (e.g. experience-sampling; Bolger \& Laurenceau, 2015) to repeatedly measure daydreams and their content as they occur over time in ecologically-valid settings. An additional benefit of this approach is that it will enable researchers to examine the longerterm outcomes of daydreaming. This is important because, in many cases, the adaptive value of daydreaming is likely to emerge over time through repeated instances of daydreaming rather than immediately after an individual daydream (cf. Baumeister, Masicampo, \& Vohs, 2011). 


\section{DAYDREAMING AND SOCIAL COGNITION}

In closing, we end by suggesting a particularly exciting line of research which would involve integrating cognitive neuroscience and social psychological approaches.

Neuroimaging work has begun to demonstrate that areas involved in daydreaming (DMN) are directly involved in goal pursuit and aspects of social cognition. One approach has been to demonstrate that these processes involve the co-activation of brain regions/networks (i.e. their functional connectivity). For example, recent work shows that the process of mentally planning personal goals involves functional coupling of regions of the DMN and executive control (Gerlach, Spreng, Madore, \& Schacter, 2014). Other research shows that the ability to imagine and successfully predict how others will behave involves functional coupling of DMN regions (Hassabis et al., 2014). One exciting possibility is that individual differences in these patterns of functional connectivity might explain variability in performance on tasks designed to measure aspects of social cognition and goal pursuit. If so, these individual neural differences could then be used to predict how the more unconstrained state of daydreaming is related to the realization of meaningful social goals in the real world. A profitable approach would be to combine task-based neuroimaging studies with experience-sampling studies that measure naturally occurring social daydreaming and later adaptive outcomes. This integrative approach would simultaneously enhance the ecological validity of neuroimaging work and provide a mechanistic and neural explanation for whether, when, and how, social daydreaming helps or hinders navigation of the social world. 
DAYDREAMING AND SOCIAL COGNITION

\section{Short Biographies}

Giulia Poerio is a post-doctoral researcher at the University of York. Giulia's research attempts to understand when and why unconstrained cognition can be adaptive, with a particular focus on the positive social and emotional outcomes that can result from imagining others. She also has a growing interest in the connections between daydreaming, dreaming, and sleep, and is an advocate of intensive longitudinal methods in ecologically valid settings. Jonathan Smallwood is a reader in the Department of Psychology at the University of York. He has worked in several different countries including Canada, Germany and the United states. The focus of his scientific work is on understanding the underlying cognitive mechanisms that support complex higher order thought, and uses both psychological and neurocognitive measures to understand this problem. 
DAYDREAMING AND SOCIAL COGNITION

\section{References}

Allen, M., Smallwood, J., Christensen, J., Gramm, D., Rasmussen, B., Gaden Jensen, C., ... Lutz, A. (2013). The balanced mind: The variability of task-unrelated thoughts predicts error-monitoring. Frontiers in Human Neuroscience, 7.

Allen, T. H., \& Honeycutt, J. M. (1997). Planning, imagined interaction, and the nonverbal display of anxiety. Communication Research, 24, 64-82.

Amft, M., Bzdok, D., Laird, A. R., Fox, P. T., Schilbach, L., \& Eickhoff, S. B. (2015). Definition and characterization of an extended social-affective default network. Brain Structure and Function, 220, 1031-1049.

Amodio, D. M., \& Frith, C. D. (2006). Meeting of minds: The medial frontal cortex and social cognition. Nature Reviews Neuroscience, 7, 268-277.

Andrews-Hanna, J. R., Kaiser, R. H., Turner, A. E., Reineberg, A. E., Godinez, D., Dimidjian, S., \& Banich, M. T. (2013). A penny for your thoughts: Dimensions of selfgenerated thought content and relationships with individual differences in emotional wellbeing. Frontiers in Psychology, 4.

Antrobus, J. S., Singer, J. L., \& Greenberg, S. (1966). Studies in the stream of consciousness: Experimental enhancement and suppression of spontaneous cognitive processes. Perceptual and Motor Skills, 23, 399-417.

Baird, B., Smallwood, J., \& Schooler, J. W. (2011). Back to the future: Autobiographical planning and the functionality of mind-wandering. Consciousness and Cognition, 20, 1604-1611.

Baird, B., Smallwood, J., Mrazek, M. D., Kam, J. W., Franklin, M. S., \& Schooler, J. W. (2012). Inspired by distraction mind wandering facilitates creative incubation. Psychological Science, 23, 1117-1122. 


\section{DAYDREAMING AND SOCIAL COGNITION}

Baumeister, R. F., \& Leary, M. R. (1995). The need to belong: Desire for interpersonal attachments as a fundamental human motivation. Psychological Bulletin, 117, 497-529.

Baumeister, R. F., Masicampo, E. J., \& Vohs, K. D. (2011). Do conscious thoughts cause behavior? Annual Review of Psychology, 62, 331-361.

Bolger, N., \& Laurenceau, J. P. (2013). Intensive longitudinal methods: An introduction to diary and experience sampling research. Guilford Press.

Brown, G. L. (1927). Daydreams: A cause of mind wandering and inferior scholarship. The Journal of Educational Research, 15, 276-279.

Buckner, R. L., Andrews-Hanna, J. R., \& Schacter, D. L. (2008). The brain's default network. Annals of the New York Academy of Sciences, 1124, 1-38.

Christoff, K. (2012). Undirected thought: Neural determinants and correlates. Brain Research, 1428, 51-59.

Christoff, K., Gordon, A. M., Smallwood, J., Smith, R., \& Schooler, J. W. (2009). Experience sampling during fMRI reveals default network and executive system contributions to mind wandering. Proceedings of the National Academy of Sciences, 106, 8719-8724.

Christoff, K., Gordon, A., \& Smith, R. (2011). The role of spontaneous thought in human cognition. In O. Vartanian and D. R. Mandel (Eds.) Neuroscience of decision making (pp. 259-284). New York: Psychology Press.

Cronbach, L. (1954). Educational psychology. London: Harcourt, Brace \& Company.

Decety, J., \& Jackson, P. L. (2006). A social-neuroscience perspective on empathy. Current Directions in Psychological Science, 15, 54-58.

Deci, E. L., \& Ryan, R. M. (2000). The" what" and" why" of goal pursuits: Human needs and the self-determination of behavior. Psychological Inquiry, 11, 227-268. 
DAYDREAMING AND SOCIAL COGNITION

Diaz, B. A., Van Der Sluis, S., Moens, S., Benjamins, J. S., Migliorati, F., Stoffers, D., ... Linkenkaer-Hansen, K. (2013). The Amsterdam Resting-State Questionnaire reveals multiple phenotypes of resting-state cognition. Frontiers in Human Neuroscience, 7.

Elliot, A. J., \& Fryer, J. W. (2008). The goal concept in psychology. In J. Shah \& W. Gardner (Eds.), Handbook of motivational science (pp. 235-250). New York: Guilford Press.

Engert, V., Smallwood, J., \& Singer, T. (2014). Mind your thoughts: Associations between self-generated thoughts and stress-induced and baseline levels of cortisol and alphaamylase. Biological Psychology, 103, 283-291.

Fox, K. C., Spreng, R. N., Ellamil, M., Andrews-Hanna, J. R., \& Christoff, K. (2015). The wandering brain: Meta-analysis of functional neuroimaging studies of mind-wandering and related spontaneous thought processes. Neuroimage, 111, 611-621.

Fox, M. D., Snyder, A. Z., Vincent, J. L., Corbetta, M., Van Essen, D. C., \& Raichle, M. E. (2005). The human brain is intrinsically organized into dynamic, anticorrelated functional networks. Proceedings of the National Academy of Sciences, 102, 96739678.

Franklin, M. S., Mrazek, M. D., Anderson, C. L., Smallwood, J., Kingstone, A., \& Schooler, J. W. (2013). The silver lining of a mind in the clouds: Interesting musings are associated with positive mood while mind-wandering. Frontiers in Psychology, 4.

Freud, S. (1908). Creative writers and day dreaming. In P.E Vernon (Ed.), Creativity. England: Penguin Books.

Freund, A. M., \& Hennecke, M. (2015). On means and ends: The role of goal focus in successful goal pursuit. Current Directions in Psychological Science, 24, 149-153.

Gerlach, K. D., Spreng, R. N., Madore, K. P., \& Schacter, D. L. (2014). Future planning: Default network activity couples with frontoparietal control network and reward- 
DAYDREAMING AND SOCIAL COGNITION

processing regions during process and outcome simulations. Social Cognitive and Affective Neuroscience, 9, 1942-1951.

Gollwitzer, P. M., \& Sheeran, P. (2006). Implementation intentions and goal achievement: A meta-analysis of effects and processes. Advances in Experimental Social Psychology, $38,69-119$.

Gorgolewski, K. J., Lurie, D., Urchs, S., Kipping, J. A., Craddock, R. C., Milham, M. P., ... Smallwood, J. (2014). A correspondence between individual differences in the brain's intrinsic functional architecture and the content and form of self-generated thoughts. PLoS One, 9, e97176.

Greicius, M. D., Krasnow, B., Reiss, A. L., \& Menon, V. (2003). Functional connectivity in the resting brain: A network analysis of the default mode hypothesis. Proceedings of the National Academy of Sciences, 100, 253-258.

Harkin, B., Webb, T. L., Chang, B. P., Prestwich, A., Conner, M., Kellar, I., ... \& Sheeran, P. (2015). Does monitoring goal progress promote goal attainment? A meta-analysis of the experimental evidence.

Harkin, B., Webb, T. L., Chang, B. P., Prestwich, A., Conner, M., Kellar, I., ... \& Sheeran, P. (2015). Does monitoring goal progress promote goal attainment? A meta-analysis of the experimental evidence. Psychological Bulletin, 14, 198-229.

Hassabis, D., Spreng, R. N., Rusu, A. A., Robbins, C. A., Mar, R. A., \& Schacter, D. L. (2014). Imagine all the people: How the brain creates and uses personality models to predict behavior. Cerebral Cortex, 24, 1979-1987.

He, J., Becic, E., Lee, Y. C., \& McCarley, J. S. (2011). Mind wandering behind the wheel performance and oculomotor correlates. Human Factors: The Journal of the Human Factors and Ergonomics Society, 53, 13-21. 


\section{DAYDREAMING AND SOCIAL COGNITION}

Holt-Lunstad, J., Smith, T. B., Baker, M., Harris, T., \& Stephenson, D. (2015). Loneliness and social isolation as risk factors for mortality: A meta-analytic review. Perspectives on Psychological Science, 10, 227-237.

Honeycutt, J. M., \& Keaton, S. A. (2012). Imagined interactions and personality preferences as predictors of relationship quality. Imagination, Cognition and Personality, 32, 3-21.

Honeycutt, J. M., Edwards, R., \& Zagacki, K. S. (1989). Using imagined interaction features to predict measures of self-awareness: Loneliness, locus of control, self-dominance, and emotional intensity. Imagination, Cognition and Personality, 9, 17-31.

Honeycutt, J. M., Vickery, A. J., \& Hatcher, L. C. (2015). The daily use of imagined interaction features. Communication Monographs, 82, 201-223.

Honeycutt, J. M., Zagacki, K. S., \& Edwards, R. (1990). Imagined interaction and interpersonal communication. Communication Reports, 3, 1-8.

Immordino-Yang, M. H., Christodoulou, J. A., \& Singh, V. (2012). Rest is not idleness: Implications of the brain's default mode for human development and education. Perspectives on Psychological Science, 7, 352-364.

Kane, M. J., Brown, L. H., McVay, J. C., Silvia, P. J., Myin-Germeys, I., \& Kwapil, T. R. (2007). For whom the mind wanders, and when: An experience-sampling study of working memory and executive control in daily life. Psychological Science, 18, 614621.

Killingsworth, M. A. \& Gilbert, D. T. (2010) A wandering mind is an unhappy mind. Science, 330, 932-932.

Klinger, E. (1975). Consequences of commitment to and disengagement from incentives. Psychological Review, 82, 1-25.

Klinger, E. (1990). Daydreaming: Using waking fantasy and imagery for self-knowledge and creativity. Los Angeles: Jeremy Tarcher Publishing. 


\section{DAYDREAMING AND SOCIAL COGNITION}

Klinger, E. (1996). Emotional influences on cognitive processing with implications for theories of both. In P. Gollwitzer, \& J. A. Bargh (Eds.), The psychology of action: Linking cognition and motivation to behavior (pp. 168-189). New York: Guilford.

Klinger, E. (2009). Daydreaming and fantasizing: Thought flow and motivation. In K. D. Markman, W. M. Klein, \& J. A. Suhr (Eds.), Handbook of imagination and mental simulation (pp. 225-239). New York: Psychology Press.

Klinger, E. (2013). Goal commitments and the content of thoughts and dreams: Basic principles. Frontiers in Psychology, 4.

Klinger, E. (2013). Goal commitments and the content of thoughts and dreams: Basic principles. Frontiers in Psychology, 4.

Klinger, E., \& Cox, M. (1988). Dimensions of thought flow in everyday life. Imagination, Cognition and Personality, 7, 105-128.

Klinger, E., Barta, S. G., \& Mahoney, T. W. (1976). Motivation, mood, and mental events. In G. Serban (Ed.), Psychopathology of human adaptation (pp. 95-112). Heidelberg: Springer.

Li, W., Mai, X., \& Liu, C. (2014). The default mode network and social understanding of others: What do brain connectivity studies tell us. Frontiers in Human Neuroscience, 8.

Mar, R. A., Mason, M. F., \& Litvack, A. (2012). How daydreaming relates to life satisfaction, loneliness, and social support: The importance of gender and daydream content. Consciousness and Cognition, 21, 401-407.

Markman, K. D., \& McMullen, M. N. (2003). A reflection and evaluation model of comparative thinking. Personality and Social Psychology Review, 7, 244-267.

Mars, R. B., Neubert, F. X., Noonan, M. P., Sallet, J., Toni, I., \& Rushworth, M. F. (2012). On the relationship between the" default mode network" and the" social brain". Frontiers in Human Neuroscience, 6. 
DAYDREAMING AND SOCIAL COGNITION

Mason, M. F., Norton, M. I., Van Horn, J. D., Wegner, D. M., Grafton, S. T., \& Macrae, C. N. (2007). Wandering minds: The default network and stimulus-independent thought. Science, 315, 393-395.

McKiernan, K. A., D'Angelo, B. R., Kaufman, J. N., \& Binder, J. R. (2006). Interrupting the “stream of consciousness": An fMRI investigation. Neuroimage, 29, 1185-1191.

McVay, J. C., \& Kane, M. J. (2013). Dispatching the wandering mind? Toward a laboratory method for cuing "spontaneous" off-task thought. Frontiers in Psychology, 4.

McVay, J. C., Kane, M. J., \& Kwapil, T. R. (2009). Tracking the train of thought from the laboratory into everyday life: An experience-sampling study of mind wandering across controlled and ecological contexts. Psychonomic Bulletin and Review, 16, 857-863.

Medea, B., Karapanagiotidis, T., Konishi, M., Ottaviani, C., Marguiles, D., Bernasconi, A., ... \& Smallwood, J. (In press). How do we decide what to do? Resting state connectivity patterns and components of self-generated thought linked to the development of more concrete personal goals. Experimental Brain Research.

Meleady, R., \& Seger, C. R. (2016). Imagined contact encourages prosocial behavior towards outgroup members. Group Processes and Intergroup Relations (online ahead of print).

Miles, E., \& Crisp, R. J. (2014). A meta-analytic test of the imagined contact hypothesis. Group Processes and Intergroup Relations, 17, 3-26.

Mooneyham, B. W., \& Schooler, J. W. (2013). The costs and benefits of mind-wandering: A review. Canadian Journal of Experimental Psychology, 67, 11-18.

Moulton, S. T., \& Kosslyn, S. M. (2009). Imagining predictions: Mental imagery as mental emulation. Philosophical Transactions of the Royal Society B: Biological Sciences, 364, 1273-1280.

Oettingen, G. (2000). Expectancy effects on behavior depend on self-regulatory thought. Social Cognition, 18, 101-129. 


\section{DAYDREAMING AND SOCIAL COGNITION}

Ottaviani, C., \& Couyoumdjian, A. (2013). Pros and cons of a wandering mind: A prospective study. Frontiers in Psychology, 4.

Poerio, G. L., Totterdell, P., \& Miles, E. (2013). Mind-wandering and negative mood: Does one thing really lead to another? Consciousness and Cognition, 22, 1412-1421.

Poerio, G. L., Totterdell, P., Emerson, L. M., \& Miles, E. (2015a). Helping the heart grow fonder during absence: Daydreaming about significant others replenishes connectedness after induced loneliness. Cognition and Emotion, 30, 1197-1207.

Poerio, G. L., Totterdell, P., Emerson, L. M., \& Miles, E. (2015b). Love is the triumph of the imagination: Daydreams about significant others are associated with increased happiness, love and connection. Consciousness and Cognition, 33, 135-144.

Poerio, G. L., Totterdell, P., Emerson, L. M., \& Miles, E. (2016). Social daydreaming and adjustment: An experience-sampling study of socio-emotional adaptation during a life transition. Frontiers in Psychology, 7.

Raichle, M. E. (2010). The brain's dark energy. Scientific American, 302, 44-49.

Raichle, M. E., MacLeod, A. M., Snyder, A. Z., Powers, W. J., Gusnard, D. A., \& Shulman, G. L. (2001). A default mode of brain function. Proceedings of the National Academy of Sciences, 98, 676-682.

Reis, H. T., \& Gable, S. L. (2003). Toward a positive psychology of relationships. In C. L. Keyes \& J. Haidt (Eds.), Flourishing: The positive person and the good life (pp. 129159). Washington, DC: American Psychological Association.

Reis, H. T., \& Gable, S. L. (2015). Responsiveness. Current Opinion in Psychology, 1, 67-71. Robison, M. K., \& Unsworth, N. (2015). Working Memory Capacity Offers Resistance to Mind-Wandering and External Distraction in a Context-Specific Manner. Applied Cognitive Psychology, 29, 680-690. 


\section{DAYDREAMING AND SOCIAL COGNITION}

Roese, N. J. (1994). The functional basis of counterfactual thinking. Journal of Personality and Social Psychology, 66, 805-818.

Ruby, F. J., Smallwood, J., Engen, H., \& Singer, T. (2013b). How self-generated thought shapes mood - the relation between mind-wandering and mood depends on the sociotemporal content of thoughts. PLoS One, 8, e77554.

Ruby, F. J., Smallwood, J., Sackur, J., \& Singer, T. (2013a). Is self-generated thought a means of social problem solving? Frontiers in Psychology, 4.

Schilbach, L., Bzdok, D., Timmermans, B., Fox, P. T., Laird, A. R., Vogeley, K., \& Eickhoff, S. B. (2012). Introspective minds: using ALE meta-analyses to study commonalities in the neural correlates of emotional processing, social and unconstrained cognition. PloS One, 7, e30920.

Schilbach, L., Eickhoff, S. B., Rotarska-Jagiela, A., Fink, G. R., \& Vogeley, K. (2008). Minds at rest? Social cognition as the default mode of cognizing and its putative relationship to the "default system" of the brain. Consciousness and Cognition, 17, 457467.

Showers, C. (1992). The motivational and emotional consequences of considering positive or negative possibilities for an upcoming event. Journal of Personality and Social Psychology, 63, 474-484.

Smallwood, J. (2013). Distinguishing how from why the mind wanders: A processoccurrence framework for self-generated mental activity. Psychological Bulletin, 139, 519-535.

Smallwood, J., \& Andrews-Hanna, J. (2013). Not all minds that wander are lost: The importance of a balanced perspective on the mind-wandering state. Frontiers in Psychology, 4. 


\section{DAYDREAMING AND SOCIAL COGNITION}

Smallwood, J., Davies, J. B., Heim, D., Finnigan, F., Sudberry, M., O'Connor, R., \& Obonsawin, M. (2004). Subjective experience and the attentional lapse: Task engagement and disengagement during sustained attention. Consciousness and Cognition, 13, 657-690.

Smallwood, J., Karapanagiotidis, T., Ruby, F., Medea, B., de Caso, I., Konishi, M., ... \& Jefferies, E. (2016). Representing representation: Integration between the temporal lobe and the posterior cingulate influences the content and form of spontaneous thought. PloS One, 11, e0152272.

Smallwood, J., Nind, L., \& O'Connor, R. C. (2009). When is your head at? An exploration of the factors associated with the temporal focus of the wandering mind. Consciousness and Cognition, 18, 118-125.

Smallwood, J., O'Connor, R. C., Sudbery, M. V., \& Obonsawin, M. (2007). Mind-wandering and dysphoria. Cognition and Emotion, 21, 816-842.

Smallwood, J., Schooler, J. W., Turk, D. J., Cunningham, S. J., Burns, P., \& Macrae, C. N. (2011). Self-reflection and the temporal focus of the wandering mind. Consciousness and Cognition, 20, 1120-1126.

Song, X., \& Wang, X. (2012). Mind wandering in Chinese daily lives-an experience sampling study. PLoS One, 7, e44423.

Stawarczyk, D., \& D'Argembeau, A. (2015). Neural correlates of personal goal processing during episodic future thinking and mind-wandering: An ALE meta-analysis. Human Brain Mapping, 36, 2928-2947.

Stawarczyk, D., Majerus, S., \& D’Argembeau, A. (2013). Concern-induced negative affect is associated with the occurrence and content of mind-wandering. Consciousness and Cognition, 22, 442-448. 


\section{DAYDREAMING AND SOCIAL COGNITION}

Stawarczyk, D., Majerus, S., Maj, M., Van der Linden, M., \& D'Argembeau, A. (2011).

Mind-wandering: Phenomenology and function as assessed with a novel experience sampling method. Acta Psychologica, 136, 370-381.

Stawarczyk, D., Majerus, S., Maquet, P., \& D’Argembeau, A. (2011). Neural correlates of ongoing conscious experience: Both task-unrelatedness and stimulus-independence are related to default network activity. PLoS One, 6, e16997.

Webb, T. L., \& Sheeran, P. (2007). How do implementation intentions promote goal attainment? A test of component processes. Journal of Experimental Social Psychology, 43, 295-302.

West, K., Turner, R., \& Levita, L. (2015). Applying imagined contact to improve physiological responses in anticipation of intergroup interactions and the perceived quality of these interactions. Journal of Applied Social Psychology, 45, 425-436.

Yarkoni, T., Poldrack, R. A., Nichols, T. E., Van Essen, D. C., \& Wager, T. D. (2011). Large-scale automated synthesis of human functional neuroimaging data. Nature Methods, 8, 665-670. 
DAYDREAMING AND SOCIAL COGNITION

\section{Figure Captions}

Figure 1. The neural overlap between daydreaming and social cognition

This figure shows the spatial overlap between key brain regions involved when the mind wanders (green) and during social cognition tasks (red). Overlap in regions of the anterior temporal lobes and posterior cingulate cortex are shown in yellow.

Figure 2. Approaches to examining the heterogeneity of daydreaming and its adaptive outcomes

The left hand side of Figure 2 shows how Multi-Dimensional Experience-Sampling is used in laboratory studies such as Ruby et al., 2013a to examine major components of self-generated thought. Participants complete a cognitive task and are randomly probed to report on the contents of their conscious experience (including whether their thoughts are focused on the task, the social, temporal, and emotional content of thought). Principal component analysis is used to explore the internal structure of this data, which is represented in the heat map at the bottom left hand corner of the Figure. Positive weightings of the different components of experience are shown in warm yellow and negative weightings are shown in cool green. The heat map presented here illustrates that self-generated thought consists of three different categories which are characterized by thoughts related to 1) the future and self, 2) the past and others, and 3) emotional valance of experience. This technique highlights the heterogeneity of the daydreaming state as well as the structure of these internal experiences which can then be related to (mal)adaptive outcomes.

The right had side of Figure 2 shows how the social content of daydreams can be related to adaptive social outcomes; in this case, the regulation of negative social feelings. The top right hand side of the figure illustrates the procedure in Poerio et al. 2015a, which manipulated the emotional context of daydreaming by inducing loneliness in participants. Participants were then randomly allocated to one of three conditions manipulating the content 


\section{DAYDREAMING AND SOCIAL COGNITION}

of self-generated experience: 1) to daydream about a positive interaction with a close significant other (social), 2) to daydream about a positive, but non-social, event (non-social), or to complete a working memory task (control). Participants were then asked to complete mood measures and to indicate their desire to connect with others in an ostensible future task. As shown by paths a1 and a 2 in the bottom right hand corner of the figure, social, but not non-social daydreamers or control participants showed increases in feelings of interpersonal connection. This demonstrates the socio-emotional regulatory benefits of the social content of self-generated thought. This portion of Figure 2 also shows the results of a mediation analysis demonstrating that the effect of social daydreaming on positive social emotion extended beyond self-reported emotion to behavioral intention. Specifically, that social daydreamers expressed less of a desire to connect with others because their sense of interpersonal connection had been replenished through imaginative activity.

\section{Figure 1}
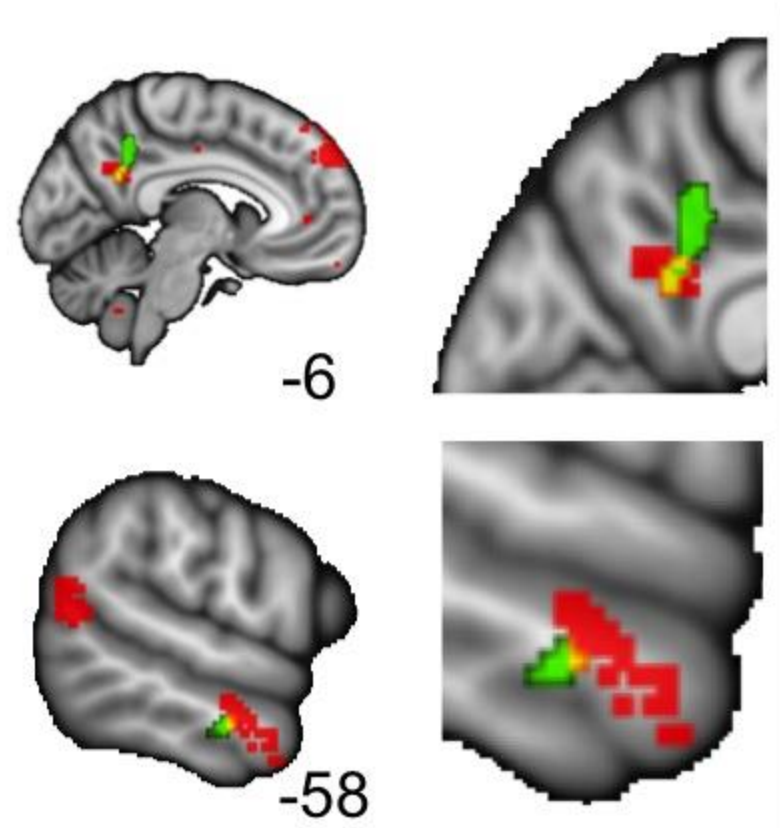

\section{Social} Cognition

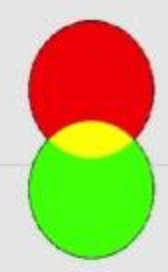

Mind wandering
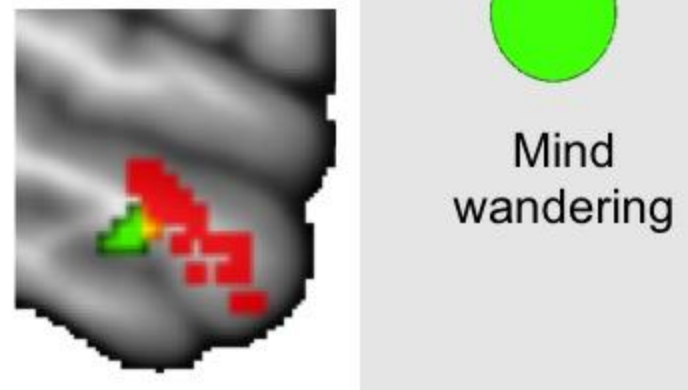

\section{Figure 2}



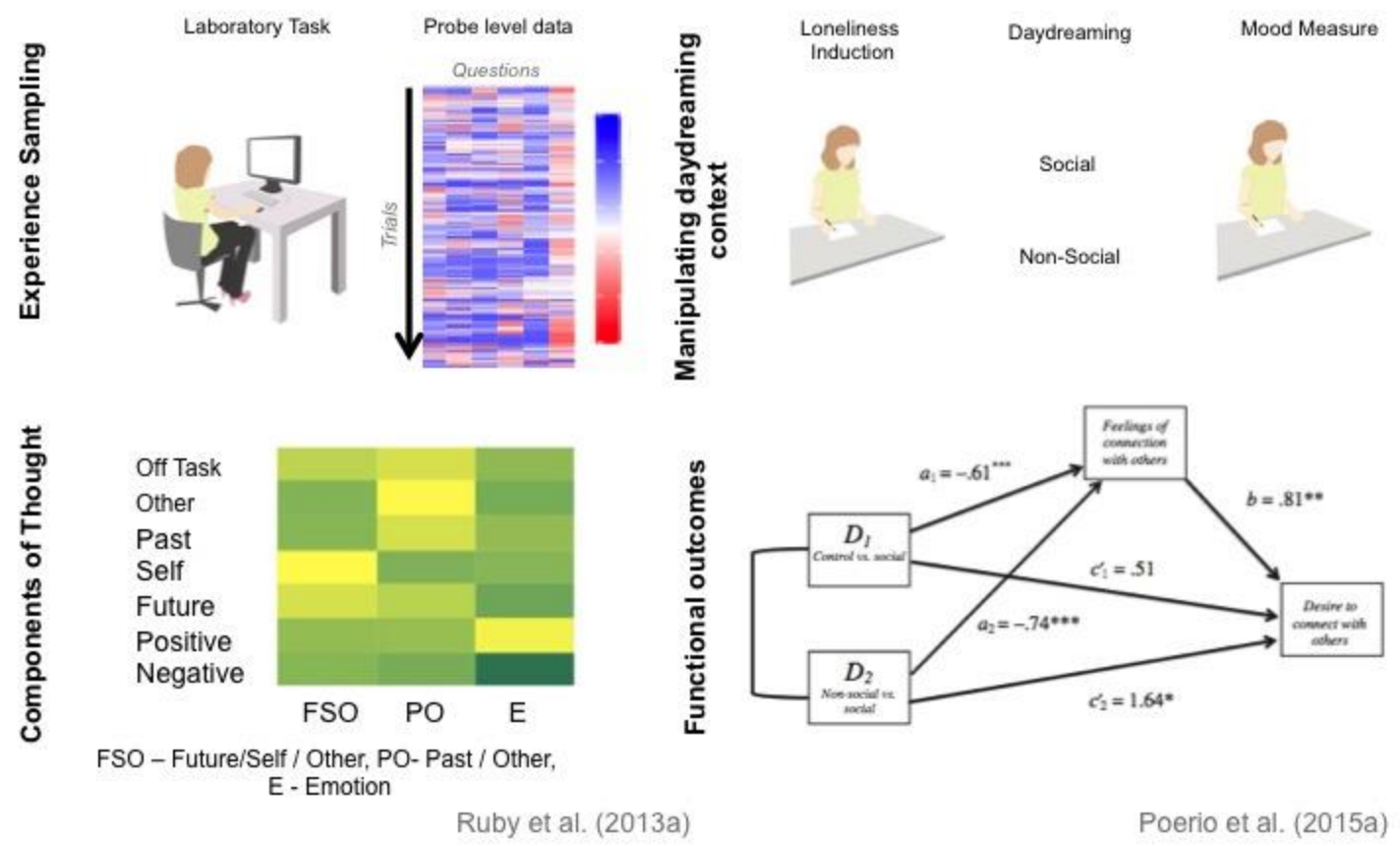